\title{
ИСПОЛЬЗОВАНИЕ БАЗЫ ДАННЫХ ООН В ИЗУЧЕНИИ ПОЛИТИКИ СТРАН В ОБЛАСТИ ВНУТРЕННЕЙ МИГРАЦИИ
}

\author{
САЛАВАТ АБЫЛКАЛИКОВ
}

\begin{abstract}
Настоящий обзор посвящен использованию Базы данных ООН о политике в области населения для исследований политики, касающейся внутренних миграџий. Такие миграции более масштабны и, возможно, даже более значимы для экономического, политического, социального и культурного развития общества, чем внешние. Несмотря на то, что многие государства в той или иной степени реализуют (или реализовали в прошлом) меры политики, относящейся к внутренним миграциям, она не всегда выделяется в качестве самостоятельной, а является составной частью других видов политики. В иелях обобщения опыта разных стран, проведения международных сопоставлений, определения региональных и глобальных тенденций в реализации политики в сфере внутренней миграџии можно использовать Базу данных о политике в области населения. База данных содержит регулярно актуализируемую информацию о ситуаџии и тенденциия реализации политики в области населения для всех государств-членов ООН и некоторых других территорий. Основным источником информации служат официальные ответь правительств стран и территорий на регулярно рассылаемые опросники Отдела народонаселения ООН. База данных предоставляет доступ к информации о политике в области народонаселения, отдельным демографическим и сочииальоэкономическим индикаторам с 1976 по 2015 г. Веб-интерфейс позволяет составлять картосхемы и графики, скачивать массивы данных о проводимой политике в табличном формате, а также содержит раздель с последними публикациями, в которых используется база данных и полезные ссылки (включая ссылки на другие базы данных по народонаселению). Вместе с тем следует отметить недостаточное раскрытие потенщиала базы данных по политике в области населения в отечественных исследованиях внутренней миграџии.
\end{abstract}

Ключевые слова: внутренняя миграция, политика в области населения, миграционная политика, расселение, база данных, ООН.

\section{МИГРАЦИОННАЯ ПОЛИТИКА - МЕЖДУНАРОДНАЯ И ВНУТРЕННЯЯ}

Несмотря на декларируемый рост численности международных мигрантов - в 1960 г. их было 92 млн, в 1990 г. в 1,7 раза, а к 2015 г. уже в 2,7 раза больше [Ozden et al. 2011; Trends in International... 2015] - внутренние миграции являются более масштабными и значимыми. Так, по обобщенным итогам переписей населения раунда 2000 г., численность международных мигрантов (людей, родившихся за границами стран своего проживания) составляла 214 млн (чуть более 3\% населения земного шара) [New trends... 2013], тогда как внутристрановых межрегиональных мигрантов (проживающих в своей стране, но за пределами родного региона - административно-территориальной единицы первого уровня) - более 740 млн (или больше, чем каждый десятый житель планеты), и есть все основания полагать, что внутрирегиональных мигрантов в мире еще больше [Bell, Muhidin 2009]. Вполне вероятно, что влияние внутренних мигрантов на экономику, политику, социальное и культурное развитие своих стран проявляется даже в большей степени, чем внешних [Ellis 2012].

САЛАВАТ ИРГАЛИЕВИЧ АБЫЛКАЛИКОВ (sabylkalikov@hse.ru), НАЦИОНАЛЬНЫЙ ИССЛЕДОВАТЕЛЬСКИЙ УНИВЕРСИТЕТ «ВЫСШАЯ ШКОЛА ЭКОНОМИКИ», РОССИЯ.

ИССЛЕДОВАНИЕ ОСУЩЕСТВЛЕНО В РАМКАХ ПРОГРАММЫ ФУНДАМЕНТАЛЬНЫХ ИССЛЕДОВАНИЙ НИУ ВШЭ В 2018 Г. СТАТЬЯ ПОСТУПИЛА В РЕДАКЦИЮ В СЕНТЯБРЕ 2018 Г. 
Естественно, что при такой массовости явления, со стороны правительств многих стран, и развитых и, еще в большей степени, развивающихся, существует запрос на реализацию определенных мер политики в области внутренней миграции. Но в отличие от политики в области международной миграции, которую традиционно имеют в виду, говоря про «миграционную политику», политика в области внутренней миграции чаще является не самостоятельной, а составной частью других видов политики: экономической, социальной, региональной, в области труда, градостроительной и городского планирования, в последние годы - политики в области устойчивого развития и др., с менее чётким выделением и объекта политики и перечня реализуемых мер [Мкртчян 2011].

Вместе с тем многие страны имеют весьма обширный опыт как проведения, так и последующего свертывания политики, которую можно охарактеризовать как «внутреннюю миграционную» или смежную с ней. $\mathrm{C}$ середины $\mathrm{XX}$ века значительная часть латиноамериканских государств реализовывала крупные программы по пространственному перераспределению населения и его массовому перемещению в малонаселенные районы. В числе этих стран Мексика, Бразилия, Венесуэла, Аргентина, Колумбия. Большинство программ в 1990-ые годы было закрыто [Пришкольник 1986; Региональная политика... 2015]. Наиболее успешной из них признана программа развития Гуаяны [Ravuri 2001], реализуемая в труднодоступной, но богатой природными ресурсами венесуэльской части Гвианского плоскогорья. В ходе её реализации были освоены обширные пространства, основаны новые города, а сам венесуэльский штат Боливар, которому принадлежит эта территория, даже несколько десятилетий конкурировал со столицей и северными прибрежными штатами в привлечении как внешних, так и внутренних мигрантов [Абылкаликов 2016].

Отечественный опыт проведения политики в области внутренней миграции весьма богат и неоднозначен. Так, политика по ограничению роста крупных городов и стимулирование заселения регионов с неблагоприятными природными условиями привели к заметной деформации территориальной структуры, перенаселенности «северов» и возникновению большого количества моногородов. Многие постоянные поселения в Сибири и на Дальнем Востоке создавались там, где они никогда бы не появились в условиях рыночной экономики [Зайончковская 1991; Пчелинцев 2004]. По оценкам начала 1990-х годов, перенаселенность российского Севера составляла порядка 20-40\% [Зайдфудим 1993]. Экономисты Всемирного банка отмечают, что если каждый третий канадец или австралиец живет в одном из трех крупнейших городов своей страны, то население России расселено по стране более равномерно, включая северные территории. Разброс населения по огромной территории и необходимость выплат значительных средств из госбюджета населению территорий с экстремальными климатическими условиями является серьезным вызовом для российской экономики [Новый взгляд... 2009]. В качестве мер развития сельских районов можно отметить кампанию по освоению целины в 1950-1960-х годах и политику ликвидации «неперспективных деревень», проводившуюся в 1960-1970-х годах. Реализация этих мер впоследствии была приостановлена, а итоги подвергнуты критике. 


\section{ИСТОЧНИКИ ИНФОРМАЦИИ БАЗЫ ДАННЫХ О ПОЛИТИКЕ В ОБЛАСТИ НАСЕЛЕНИЯ И ЕЁ ОСНОВНЫЕ ВОЗМОЖНОСТИ}

Существует авторитетный источник информации, который может быть полезен при решении непростых задач исследования и обобщения опыта разных стран, проведения международных сопоставлений и определения региональных и глобальных тенденций в реализации политики в сфере внутренней миграции - База данных (БД) о политике в области населения [World Population Policies... 2018], поддерживаемая Департаментом по экономическим и социальным вопросам ООН. База данных содержит регулярно актуализируемую информацию о ситуации и тенденциях реализации политики в области народонаселения для государств-членов ООН (на данный момент их 193), двух страннаблюдателей (Палестина и Ватикан), а также островов Кука и Ниуэ, не являющихся членами Организации Объединенных Наций. Число стран и территорий, включенных в базу данных, росло от раунда к раунду (от 150 в 1976 г. до 197 к раундам 2013 и 2015 гг.).

Эта БД довольно активно используется отечественными демографами, исследующими вопросы репродуктивного поведения и планирования семьи, изменения численности населения, а также старения [Щербакова 2016; Иванов 2017; Сакевич 2018], но до сих пор мало востребована исследователями миграции, особенно внутренней. В качестве положительного примера можно привести лишь небольшое число научных работ, среди которых обзор Е.М. Щербаковой [2014] о политике в области международной миграции. Вместе с тем БД может быть полезна специалистам, интересующимся и другими проблемами народонаселения, так как охватывает эволюцию взглядов и проводимой политики правительств стран мира по семи основным темам: численность и рост населения; возрастная структура населения; рождаемость; репродуктивное здоровье и планирование семьи; здоровье и смертность; пространственное распределение населения и внутренняя миграция; международная миграция.

Данные в БД приводятся в динамике с 1976 по 2015 г., всего на сегодняшний день доступно 11 контрольных точек (раундов), к которым относится информация. В последнее время обновления происходят примерно раз в два года. Основным источником информации служат официальные ответы правительств стран и территорий (точнее, государственных органов, отвечающих за проведение политики в области народонаселения и социального развития) на регулярные запросы Отдела народонаселения ООН в виде опросников (анкет) ${ }^{1}$. На данный момент запущен опросник 12-го раунда (только по модулю «Международная миграция»), причем в последних раундах анкету можно было заполнять как в бумажном варианте, так и в электронном виде. Также используются официальные публикации, нормативно-правовые документы (законодательные акты, государственные программы и др.); доклады и публикации международных организаций, фондов, межправительственных комиссий и др.; научные публикации, материалы исследовательских центров, экспертные оценки и материалы СМИ.

\footnotetext{
${ }^{1}$ URL: https://esa.un.org/PopPolicy/Inquiry.aspx (дата обращения: 14.12.2018).
} 
В одиннадцатом, последнем на данный момент, опроснике содержатся 3 модуля:

1. численность населения, его рост и распределение;

2. рождаемость, планирование семьи и репродуктивное здоровье;

3. международная миграция.

Данные о политике в области внутренней миграции за 2015 г. представлены в первом модуле «Численность населения, его рост и распределение» в разделе D «Распределение населения и урбанизация»; в предыдущих раундах тема «Пространственное распределение и внутренняя миграция» составляла отдельный модуль (а всего в предыдущих раундах модулей было 6-7). Кроме того, в модуле III за 2015 г., посвященном международной миграции, содержится раздел $\mathrm{C}$ «Circular and return migration», который в русскоязычной версии анкеты озаглавлен как «Маятниковая и возвратная миграция». По-видимому, здесь речь идет о неудачном переводе, так как в отечественной академической традиции под «маятниковой миграцией» понимаются регулярные перемещения из одного населенного пункта в другой на учебу или работу в течение светового дня (суток), включая внутрирегиональные и межрегиональные в пределах одной страны (например, из Московской области в Москву и обратно), а не международная временная трудовая миграция. Таким образом, этот раздел также относится к политике, регулирующей международную миграцию.

В разделе «Распределение населения и урбанизация» на 2015 г. рассмотрены вопросы географического распределения населения внутри регионов страны, между городом и селом, а также среди городских агломераций. Раздел опросника включает один закрытый вопрос (пп. 1.13 опросника) и три вопроса (пп. 1.14-1.16), в которых надо выбрать из ответов «да», «нет» или «не применимо» по каждому пункту-закрытию (мере проводимой политики или стратегии), а в последний пункт можно вписать свой вариант, если представленные выше в перечне меры политики не подходят. Кроме того, правительствам предложено предоставить копии документов, которые могут быть соотнесены с мерами политики, перечисленными в модуле опросника. По большому счету в последних трех вопросах обобщен и перечислен основной арсенал имеющихся мер политики в области внутренней миграции, поэтому приведем вопросы последней на текущий момент анкеты полностью (таблица 1).

Эти вопросы и ответы со стороны правительств на них и являются информационной основой БД. Как уже отмечено выше, время от времени меняется структура основных модулей базы данных, а также формулировки задаваемых в анкете вопросов. В таблице 2 приведена информация о содержании в БД разных показателей ${ }^{2}$, касающихся политики в области пространственного распределения населения и внутренней миграции. Таким образом, к раунду 2015 г. структура показателей была существенно пересмотрена по сравнению с предыдущими.

\footnotetext{
${ }^{2}$ URL: https://esa.un.org/PopPolicy/Metadata.aspx (дата обращения: 14.12.2018). 
Таблица 1. Раздел «Распределение населения и урбанизация» опросника ООН по проблемам народонаселения и развития для правительств

1.13 Каково мнение правительства о нынешнем территориальном распределении населения в пределах страны?

- Желательны коренные изменения.

- Желательны незначительные изменения.

- Удовлетворительно, нежелательны изменения.

- Официальной позиции нет.

1.14 Приняло ли правительство (в последние пять лет) политику или стратегию, поощряющую любой из следующих видов перераспределения населения?

a. Снижение миграционного потока (миграции) из сельских районов в города.

b. Снижение миграции в крупные городские агломерации.

c. Децентрализация крупных городских центров в менее крупные города, пригородные или сельские районы.

d. Трудовая миграция, отвечающая потребностям конкретного региона.

е. Переселение в малонаселенные районы.

f. Переселение из экологически уязвимых или опасных районов.

g. Прочее (просьба указать).

1.15 Какой из нижеследующих видов политики или стратегий был принят правительством (в последние пять лет) в иеелях поощрения развития сельских районов?

a. Создание занятости в сельских районах.

b. Стимулы для создания или сохранения производства в сельских районах.

c. Перемещение производства из больших городских центров в сельские районы.

d. Развитие сельской инфраструктуры и объектов.

е. Аграрная реформа.

f. Прочее (просьба указать).

1.16 Какой из нижеследующих видов политики или стратегий был принят правительством (в последние пять лет) в целях улучшения условий жизни и средств существования в крупных городских ичентрах?

a. Повышение энергоэффективности в транспортной области и жилищном секторе.

b. Более жесткие предельно допустимые уровни загрязнения для автотранспорта.

c. Более жесткие экологические нормы для промышленных отраслей внутри крупных городских центров или вокруг них.

d. Совершенствование системы управления ликвидацией твердых отходов.

е. Улучшение доступа к паркам, игровым площадкам и другим общественным местам.

f. Обеспечение доступа к воде и санитарии для городских бедняков.

g. Обеспечение доступа к образованию и медицинским услугам для городских бедняков.

h. Обеспечение возможностей землевладения и надлежащие жилищные условия для городских бедняков.

i. Обеспечение общественной безопасности.

j. Прочее (просьба указать).

Источник: [World Population Policies... 2018]. 


\section{Таблица 2. Доступность показателей пространственного распределения и внутренней миграции по раундам}

\begin{tabular}{|c|c|c|c|c|c|c|c|c|c|c|c|}
\hline Показатели & $\frac{0}{2}$ & $\begin{array}{l}\infty \\
\infty \\
\stackrel{2}{二}\end{array}$ & ๙̊ & ঠ্ণ & $\stackrel{\overbrace{}}{\varnothing}$ & ๖̊ & 요 &  & $\overline{\bar{\delta}}$ & $\stackrel{m}{\frac{\pi}{2}}$ & $\frac{n}{\delta}$ \\
\hline $\begin{array}{l}\text { Мнение правительств о пространственном } \\
\text { распределении } \\
\text { Политика по пространственному распределению } \\
\text { населения }\end{array}$ & $\mathrm{X}$ & $\mathrm{X}$ & $\mathrm{X}$ & $\mathrm{X}$ & $\mathrm{X}$ & $X$ & $\mathrm{X}$ & $\mathrm{X}$ & $\mathrm{X}$ & $\mathrm{X}$ & $\mathrm{X}$ \\
\hline $\begin{array}{l}\text { Политика в области распределения населения между } \\
\text { регионами }\end{array}$ & $\mathrm{X}$ & $\mathrm{X}$ & $\mathrm{X}$ & $\mathrm{X}$ & $\mathrm{X}$ & & & & & & \\
\hline $\begin{array}{l}\text { Политика в области распределения населения между } \\
\text { сельскими и городскими районами }\end{array}$ & $\mathrm{X}$ & $\mathrm{X}$ & $\mathrm{X}$ & $\mathrm{X}$ & $\mathrm{X}$ & & & & & & \\
\hline Политика в области миграции из сел в города & $\mathrm{X}$ & $\mathrm{X}$ & $X$ & $\mathrm{X}$ & $\mathrm{X}$ & $X$ & $\mathrm{X}$ & $\mathrm{X}$ & $\mathrm{X}$ & $\mathrm{X}$ & \\
\hline Политика в области миграции из сел в села & & & & & & $X$ & $\mathrm{X}$ & $\mathrm{X}$ & & & \\
\hline Политика в области миграции из городов в села & & & & & & $X$ & $\mathrm{X}$ & $\mathrm{X}$ & & & \\
\hline Политика в области миграции из городов в города & & & & & & $\mathrm{X}$ & $\mathrm{X}$ & $\mathrm{X}$ & & & \\
\hline $\begin{array}{l}\text { Политика в области миграции в городские агломерации } \\
\text { Политика в области развития сельских районов }\end{array}$ & $\mathrm{X}$ & $\mathrm{X}$ & $\mathrm{X}$ & $\mathrm{X}$ & $\mathrm{X}$ & $\mathrm{X}$ & $\mathrm{X}$ & $\mathrm{X}$ & $\mathrm{X}$ & & $X$ \\
\hline $\begin{array}{l}\text { Политика в отношении условий жизни и устойчивости } \\
\text { городских центров }\end{array}$ & & & & & & & & & & & \\
\hline
\end{tabular}

Источник: [World Population Policies... 2018].

Веб-интерфейс базы данных позволяет пользователю запрашивать информацию по проводимой политике (Policies ${ }^{3}$ ), а также по отдельным демографическим и социальноэкономическим показателям/индикаторам (Indicators ${ }^{4}$ ) как для всех стран мира вместе, так по группам стран и отдельно по конкретным странам за выбранные временные отметки (c 1976 по 2015 г.), создавать графики (раздел Summary Graphs ${ }^{5}$ ) и карты (Thematic Maps ${ }^{6}$ ).

Прежде чем начать работать с БД о политике в области населения, следует ознакомиться с определениями переменных политики (Definitions of Policy Variables ${ }^{7}$ ) и используемых в базе индикаторов (Definitions of Indicators ${ }^{8}$ ), так как частично меры проводимой политики зашифрованы в неинтуитивном виде. Так, переменная «Политика по пространственному распределению населения» может иметь 3 варианта значений (в соответствующей таблице с ответом на запрос пользователя будут указаны только цифры, а также «ничего из вышеперечисленного» или прочерк при отсутствии данных):

1. сокращение миграции из сельской местности в города;

2. децентрализация крупных городских центров в менее крупные города, пригородные или сельские районы;

3. переселение из экологически уязвимых или опасных районов.

Индикаторы, используемые в БД, по большей части являются общепринятыми. К примеру, плотность населения (измеряемая как отношение среднегодовой численности

\footnotetext{
${ }^{3}$ URL: https://esa.un.org/PopPolicy/cprofile.aspx?MainMenu\&Type=Variables (дата обращения: 14.12.2018).

${ }^{4}$ URL: https://esa.un.org/PopPolicy/cprofile.aspx?MainMenu\&Type=Indicators (дата обращения: 14.12.2018).

${ }^{5}$ URL: https://esa.un.org/PopPolicy/charting/graphs.aspx (дата обращения: 14.12.2018).

${ }^{6}$ URL: https://esa.un.org/PopPolicy/charting/worldmaps.aspx (дата обращения: 14.12.2018).

${ }^{7}$ URL: https://esa.un.org/PopPolicy/img/Definitions_of_Policy_Variables.pdf (дата обращения: 14.12.2018).

${ }^{8}$ URL: https://esa.un.org/PopPolicy/img/Definitions_of_Indicators.pdf (дата обращения: 14.12.2018). 
населения страны к площади ее территории), индекс человеческого развития (ИЧР, показатель, заменивший ИРЧП). Кроме того, используются и некоторые специфические показатели развития (доля сельского населения, имеющего доступ к электроэнергии, чистой воде, канализации в городах и сельской местности и др.), поэтому ознакомление с определениями используемых индикаторов также является весьма полезным.

База данных позволяет построить картосхемы по выбранным показателям (мерам проводимой политики) на уровне всего мира, а также макрорегионов мира (OOH): Азия, Европа, Африка, Северная Америка, Южная Америка, Центральная Америка, Океания, Ближний Восток с 1976 по 2015 г. Однако у БД есть ограничения: картосхемы можно построить лишь для тех переменных, которые содержат только одну меру политики (при попытке построить картосхему с несколькими мерами политики БД выдает ошибку) ${ }^{9}$, также требуется браузер с поддержкой устаревающей технологии Adobe Flash.

На рисунке 1 представлено мнение правительств о нынешнем территориальном распределении населения в пределах страны на 2013 г. и 3 варианта ответа (желательны коренные изменения; желательны незначительные изменения; удовлетворительно, изменения нежелательны). На рисунке 2 аналогичная информация на 1996 и 2013 г., но в графиках (столбчатых диаграммах).

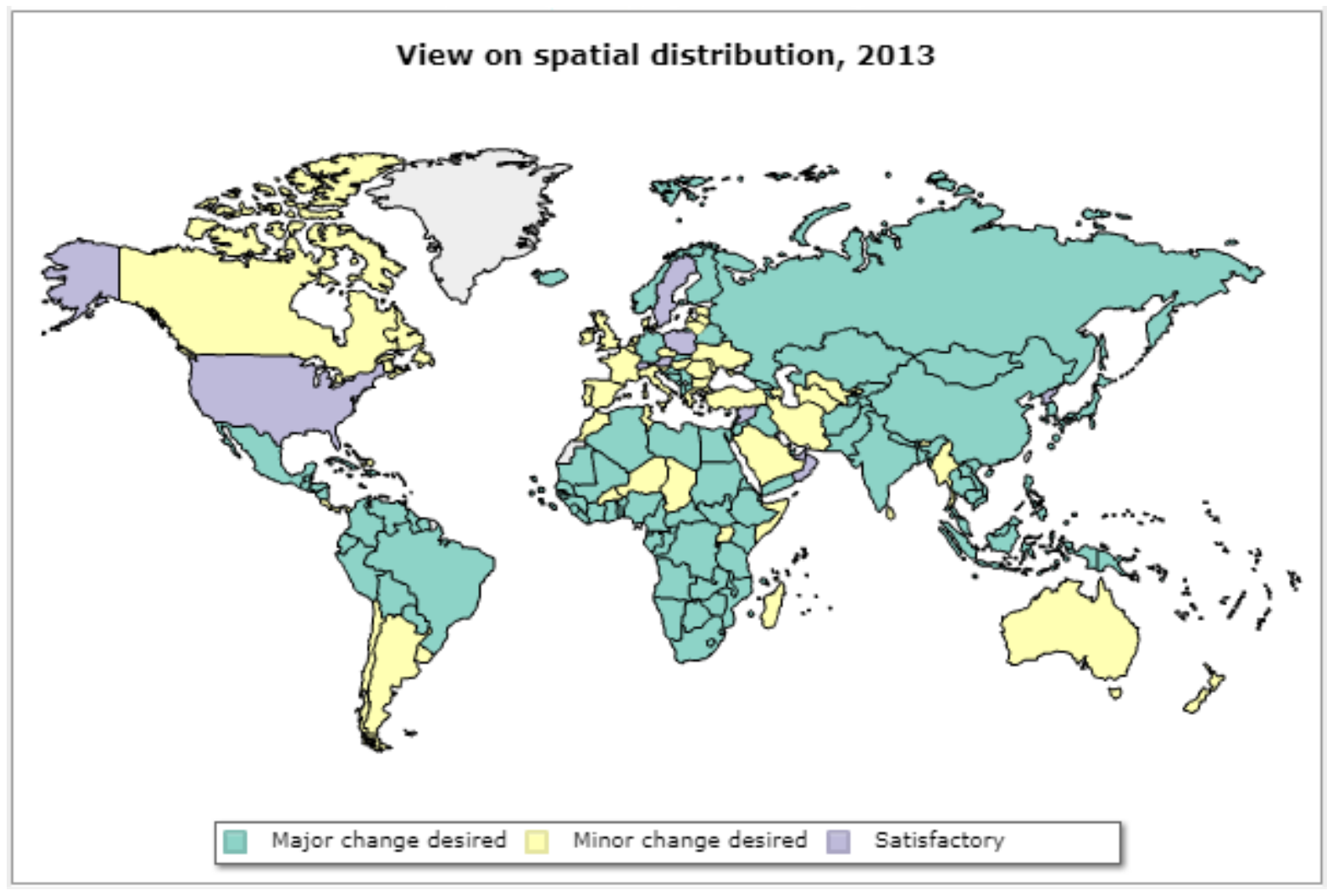

Рисунок 1. Пример построения картосхемы в БД о политике в области населения Источник: [World Population Policies... 2018].

\footnotetext{
${ }^{9}$ По этой причине не удалось построить картосхемы, а также графики по данным за 2015 г.
} 
Создателями БД предусмотрена возможность экспортировать полученные картосхемы и графики в формате PDF и JPG, однако у автора данного обзора попытки экспорта ни в одном из установленных браузеров не увенчались успехом.



Рисунок 2. Пример построения графиков БД о политике в области населения

Источник: [World Population Policies... 2018].

Кроме того, БД о политике в области населения позволяет скачивать массивы с информацией о проводимой политике по всем странам мира по каждому году как целиком, так и по отдельным тематическим модулям в формате Excel в специальном разделе Population Policies Datasets ${ }^{10}$. Это весьма удобно и фактически позволяет скачать базу данных по мерам политики целиком за отдельные раунды. Правда, по социальноэкономическим показателям/индикаторам такой возможности нет.

Для наглядной демонстрации возможностей БД приведем таблицу 3, в которой размещена информация о политике в области численности населения, его росте и распределении для Аргентины, Австралии, Канады, Республики Казахстан и Российской Федерации на 2015 г. Названные страны схожи по параметрам пространственной организации общества (огромные территории и небольшая для таких территорий численность населения, вследствие чего для этих государств характерно сочетание низкой

${ }^{10}$ URL: https://esa.un.org/PopPolicy/wpp_datasets.aspx (дата обращения: 14.12.2018). 
плотности населения с сильными региональными диспропорциями в распределении населения).

\section{Таблица 3. Политика в области численности населения, его роста и распределения, 2015}

\begin{tabular}{l|l|c|c|c}
\hline Страна & $\begin{array}{c}\text { Политика по росту } \\
\text { численности } \\
\text { населения }\end{array}$ & $\begin{array}{c}\text { Политика по } \\
\text { пространственному } \\
\text { распределению } \\
\text { населения* }\end{array}$ & $\begin{array}{c}\text { Политика в области } \\
\text { развития сельских } \\
\text { районов** }\end{array}$ & $\begin{array}{c}\text { Политика в } \\
\text { отношении условий } \\
\text { жизни и } \\
\text { устойчивости } \\
\text { городских } \\
\text { центров*** }\end{array}$ \\
\hline Аргентина & $\begin{array}{l}\text { Нет официальной } \\
\text { политики }\end{array}$ & 1 & $1,2,3$ & $1,2,3,4,5$ \\
Австралия & Невмешательство & 1,2 & 1,3 & $1,2,3,4,5$ \\
Канада & Невмешательство & 1 & 1,3 & $1,3,5$ \\
Россия & Повышение & 1,2 & 1,3 & $3,4,5$ \\
\hline
\end{tabular}

Источник: [World Population Policies... 2018].

Примечания: *-Варианты ответа: 1. Сокращение миграции из сельской местности в города. 2. Децентрализачия крупных городских ичентров в менее крупные города, пригородные или сельские районы. 3. Переселение из экологически уязвимых или опасных районов.

** - Варианты ответа: 1. Стимулирование создания или развития отраслей экономики в сельских районах. 2. Перемещение отраслей экономики из крупных городских иентров в сельские районы. 3. Развитие сельской инфраструктуры и объектов (условий).

***_- Варианты ответа: 1. Повышение энергоэффективности транспорта и жилья. 2. Ужесточение экологических нормативов для промышленности в крупных городских ичентрах или вокруг них.

3. Совериенствование утилизации ТБО. 4. Обеспечение доступа к воде и санитарии для бедных, живущих в городах. 5. Обеспечение землепользования и достаточного обеспечения жильем для бедных, живущих в городах.

\section{ДОПОЛНИТЕЛЬНЫЕ РАЗДЕЛЫ БД}

База данных содержит каталог полезных ссылок ${ }^{11}$ на международные программы, другие базы данных по политике в области народонаселения и ссылки на партнерские международные организации, a также библиотеку последних публикаций ${ }^{12}$ по разнообразному спектру тем политики в области населения, в которых используется информация БД об этой политике: низкая рождаемость, аборты и репродуктивное здоровье, международная миграция, пространственное распределение населения (включая урбанизацию и внутреннюю миграцию).

Так, в буклете «Политика в области пространственного распределения и урбанизации» [United Nations... 2016], составленном преимущественно по данным БД о политике в области населения, содержится обобщающая характеристика проводимой

${ }^{11}$ URL: https://esa.un.org/PopPolicy/usefullinks.aspx (дата обращения: 14.12.2018).

${ }^{12}$ URL: https://esa.un.org/PopPolicy/publications.aspx (дата обращения: 14.12.2018). 
правительствами стран политики за последние 5 лет. Отмечается, что в ответ на тенденцию роста урбанизации в странах Африки и Азии (и в целом в мире), в особенности роста агломераций численностью свыше 5 млн человек, 87\% африканских и 72\% азиатских стран проводят политику по сокращению миграции из сельских районов в города. Правительства менее развитых стран охотнее проводят политику по сокращению сельско-городских миграций (таковых 78\% от их общего числа) и политику по децентрализации крупнейших агломераций (47\% развивающихся стран), тогда как среди более развитых стран только $51 \%$ пытаются сократить сельско-городские миграции (в Европе - 48\%). Политику по децентрализации городских агломераций проводят всего лишь в 17\% развитых стран.

Почти все страны мира (98\%) проводят политику по развитию сельской инфраструктуры. Страны с более высоким уровнем доходов (и большим объемом выбросов $\mathrm{CO}_{2}$ на душу населения) проводят политику, направленную на повышение энергоэффективности транспорта и жилищного строительства, среди стран со средним уровнем доходов таких большинство, а среди стран с низкими доходами - пока еще меньшинство. С другой стороны, именно в бедных странах правительства декларируют, что уделяют больше внимания политике улучшения доступа к чистой воде и канализации, увеличения доступности жилья и улучшения условий жизни обитателей трущоб, тогда как для более развитых стран такие вопросы уже менее актуальны.

К существенным недостаткам базы данных следует отнести нерешенную проблему сопоставимости содержащихся в ней сведений. Так, понятие «малонаселенные районы» весьма неодинаково для стран с разной численностью и плотностью населения, площадью территории и географическим положением. К примеру, считающиеся малонаселенными территории для Нидерландов или Бангладеш несопоставимы с малонаселенными районами для России или Монголии. Некоторые страны и территории имеют крайне небольшую


Науру, Маршалловы Острова, Тувалу, тогда как Казахстан, Аргентина или Алжир - более 2 млн км². Кроме того, понятия «урбанизация», «городские» и «сельские» районы также поразному определяются в каждой конкретной стране. Соответственно, перемещения населения, которые считаются миграцией по направлению «село-город» (а также «городсело», «село-село» и «город-город») в одних странах, могут трактоваться по-иному в других. Если для выявления объемов международной миграции используется довольно универсальный критерий рождения в другой стране (а в случае отсутствия такой информации - об иностранном гражданстве), то выявление единого критерия определения внутренних мигрантов представляется более трудной задачей.

\section{ЗАКЛЮЧЕНИЕ}

База данных о политике в области населения не удовлетворяет некоторым требованиям «идеальности» [Винник 2012]: она содержит неточности, временами «зависает» и не выдает информацию (особенно при запросе больших массивов данных), имеет не самый дружественный интерфейс и не предусматривает возможности сохранения URL-доступа непосредственно к конкретной таблице (показателю). Вместе с тем БД бесплатна, охватывает абсолютное большинство стран мира, регулярно обновляется, а главное, 
содержит уникальную информацию, полученную «из первых рук» - от правительств стран, которые непосредственно и реализуют политику в области народонаселения. К сожалению, база данных не дает доступ к самим анкетам (опросникам). Так, исследовательский интерес могли бы вызвать нормативные акты и другие документы, на которые ссылаются государственные органы, непосредственно заполняющие анкеты.

Крупный специалист и создатель нескольких демографических баз данных (включая приложения ${ }^{13}$ демографического журнала «Демоскоп Weekly») Е.Л. Сороко отмечает: «Информация, которую можно почерпнуть в базах данных демографических показателей, выполняет ряд важных функций. Это, прежде всего, «сырье», основа для анализа» [Сороко 2012]. И действительно, в этом плане БД о политике в области населения может послужить весьма полезным источником «сырья» для дальнейших демографических исследований. База данных позволяет провести международные сравнения, а также посмотреть эволюцию взглядов правительств и мер политики в области внутренней миграции (и других проблем народонаселения) за последние четыре десятилетия. Надеемся, что с течением времени востребованность базы данных среди отечественных исследователей повысится.

\section{ЛИТЕРАТУРА}

Абылкаликов С.И. (2016). Как люди переезжают в разных странах: мировой опыт изучения пожизненной миграции // Псковский регионологический журнал. 1(25): 4558.

Винник М.В. (2012). Какой должна быть идеальная демографическая База данных? // Демоскоп Weekly. 533-534 URL: http://www.demoscope.ru/weekly/2012/0533/analit06.php (дата обращения: 12.09.2018).

Зайдфудим П.Х. (1993). Реабилитация жизненной среды российского Севера. М.: Госкомсевер России. 67 с.

Зайончковская Ж.А. (1991). Демографическая ситуация и расселение. М.: Наука. 135 с.

Иванов С.Ф. (2017). Детерминанты демографического перехода на глобальном Юге // Демографическое обозрение 4(2). URL: https://doi.org/10.17323/demreview.v4i2.7102 (дата обращения: 12.09.2018).

Мкртчян Н.В. (2011). Нужна ли России политика в области внутренней миграции? М.: МАКС Пресс. 36 c.

Новый взгляд на экономическую географию. Доклад о мировом развитии 2009 (2009). Вашингтон, Округ Колумбия: Всемирный Банк: 384 с. URL: http://siteresources.worldbank.org/INTWDR2009/Resources/42310061225840759068/WDR09_OVERVIEW_RU_Web.pdf (дата обращения: 12.09.2018).

Пришкольник Д.Б. (1986). Опыт хозяйственного освоения новых районов в Мексике, Венесуэле и Бразилии. Некоторые закономерности и различия // Латинская Америка: хозяйственное освоение новых территорий / Под ред. Тарасова К.С. М.: ИЛА АН CCCP. 189 c.

${ }^{13}$ URL: http://www.demoscope.ru/weekly/pril.php (дата обращения: 14.12.2018). 
Пчелинцев О.С. (2004). Переход от урбанизации к субурбанизации / Региональная экономика в системе устойчивого развития. М.: Наука: 44-51. URL: http://demoscope.ru/weekly/2005/0219/analit04.php (дата обращения: 12.09.2018).

Региональная политика: зарубежный опыт и российские реалии (2015) / Под ред. А.В. Кузнецова, О.В. Кузнецовой. М.: ИМЭМО РАН. 137 с.

Сакевич В.И. (2018). Политика в области репродуктивного здоровья в регионах и странах мира // Демоскоп Weekly. 777-778. URL: http://demoscope.ru/weekly/2018/0777/barom01.php (дата обращения: 12.09.2018).

Сороко Е.Л. (2012). Критерии качества демографических баз данных // Демографическое развитие: вызовы глобализации. Седьмые Валентеевские чтения. Материалы международной конференции / Под общ. ред.: В.А. Ионцева, Н.В. Зверевой, Г.Е. Ананьевой, В. П. Тышкевич. М.: МАКС Пресс: 130-131.

Щербакова Е.М. (2014). Международная миграция и миграционная политика // Демоскоп Weekly. 597-598. URL: http://demoscope.ru/weekly/2014/0597/barometer597.pdf (дата обращения: 12.09.2018).

Щербакова Е.M. (2016). Старение населения и устойчивое развитие // Демоскоп Weekly. 709-710. URL: http://www.demoscope.ru/weekly/2016/0709/barometer709.pdf (дата обращения: 12.09.2018).

Bell M., S. Muhidin (2009). Cross-national comparisons of internal migration. Human Development Research Paper. 2009/30. New York: United Nations Development Programme.

Ellis M. (2012). Reinventing US internal migration studies in the age of international migration // Population, space and place. 2(18): 196-208.

New trends in migration: demographic aspects (2013). Report of the Secretary-General. United Nations, N.Y.: UN.

Ozden C., C.R. Parsons, M. Schiff, T.L. Walmsley (2011). Where on Earth is everybody? The evolution of global bilateral migration 1960-2000 // The World Bank Economic Review. 1 (25): $12-56$.

Ravuri E.D. (2001). Migration in Venezuela, 1950-1990: A Reassessment of the Guayana Project. University of Cincinnati. $471 \mathrm{p}$.

Trends in International Migrant Stock: The 2015 Revision (2015). New York: United Nations Department of Economic and Social Affairs, Population Division.

United Nations, Department of Economic and Social Affairs, Population Division (2016). Policies on Spatial Distribution and Urbanization: Data Booklet (ST/ESA/ SER.A/394) URL: http://www.un.org/en/development/desa/population/publications/pdf/policy/Data\%20Booklet \%20Urbanization\%20Policies.pdf (дата обращения: 12.09.2018).

World Population Policies Database: The 2015 Revision (2018). URL:

https://esa.un.org/PopPolicy/about_database.aspx (дата обращения: 12.09.2018). 


\title{
USING THE WORLD POPULATION POLICIES DATABASE TO STUDY INTERNAL MIGRATION POLICY
}

\author{
SALAVAT ABYLKALIKOV
}

\begin{abstract}
This paper investigates the use of the United Nations World Population Policies Database for research on internal migration policy. Internal migration is more extensive and, perhaps, even more significant for the economic, political, social and cultural development of society than international migration. Internal migration policy is not always singled out as an independent factor, but is generally treated as a part of other types of policies.

In order to summarize the experience of different countries, conduct international comparisons and identify regional and global tendencies in the implementation of policies on internal migration, the World Population Policy Database can be used. The database contains regularly updated information on the situation and trends in the implementation of population policy for all UN member states and some other territories. The main source of information is the official responses of the governments of these countries and territories to regularly distributed inquiries of the UN Population Division.
\end{abstract}

The database provides access to information about population policy and some demographic and socioeconomic indicators from 1976 to 2015. The web interface makes it possible to create maps and graphs and to download datasets of policy data in the Excel format, and also contains sections with the latest publications that use the database and useful links (including links to other demographic databases). At the same time, it should be noted that the potential of the database on population policy for Russian studies on internal migration has not been adequately exploited.

Key words: internal migration, population policy, migration policy, resettlement, database, UN.

Salavat Abylkalikov (sabylkalikov@hse.ru), National Research University Higher School of Economics, RUSSIA.

THIS WORK IS AN OUTPUT OF A RESEARCH PROJECT IMPLEMENTED AS PART OF THE BASIC RESEARCH PROGRAM AT THE NATIONAL RESEARCH UNIVERSITY HighER SCHOOL OF ECONOMICS (HSE).

DATE RECEIVED: SEPTEMBER 2018.

\section{REFERENCES}

Abylkalikov S.I. (2016). Kak lyudi pereezzhayut v raznykh stranakh: mirovoy opyt izucheniya pozhiznennoy migratsii [Migration in different countries: world research experience of lifetime migration] // Pskovskiy regionologicheskiy zhurnal [Pskov Regionological Journal]. 1(25): 45-58.

Bell M., S. Muhidin (2009). Cross-national comparisons of internal migration. Human Development Research Paper. 2009/30. New York: United Nations Development Programme.

Ellis M. (2012). Reinventing US internal migration studies in the age of international migration // Population, space and place. 2(18): 196-208.

Ivanov S.F. (2017). Determinanty demograficheskogo perekhoda na global'nom Yuge [Determinants of the demographic transition in the Global South]. Demograficheskoe obozrenie [Demographic review]. 4(2). URL: https://doi.org/10.17323/demreview.v4i2.7102 (accessed: 12.09.2018). 
Mkrtchyan N.V. (2011). Nuzhna li Rossii politika v oblasti vnutrenney migratsii? [Does Russia need an Internal Migration Policy?]. Moscow: MAKS Press. 36 p.

New trends in migration: demographic aspects (2013). Report of the Secretary-General. United Nations, N.Y.: UN.

Novyy vzglyad na ekonomicheskuyu geografiyu. Doklad o mirovom razvitii 2009 (2009) [World development report 2009: reshaping economic geography]. Washington, DC: Vsemirnyy Bank [World Bank]: 384 p. URL: http://siteresources.worldbank.org/INTWDR2009/Resources/42310061225840759068/WDR09_OVERVIEW_RU_Web.pdf (accessed: 12.09.2018).

Ozden C., C.R.Parsons, M. Schiff, T.L. Walmsley (2011). Where on Earth is everybody? The evolution of global bilateral migration 1960-2000 // The World Bank Economic Review. 1 (25): $12-56$.

Pchelintsev O.S. (2004). Perekhod ot urbanizatsii k suburbanizatsii [The transition from urbanization to suburbanization] / Regional'naya ekonomika v sisteme ustoychivogo razvitiya [Regional economy in the system of sustainable development]. Moscow: Nauka: 44-51. URL: http://Demoscope.ru/weekly/2005/0219/analit04.php (accessed: 12.09.2018)

Prishkolnik D.B. (1986). Opyt khozyaystvennogo osvoeniya novykh rayonov v Meksike, Venesuele i Brazilii. Nekotorye zakonomernosti i razlichiya [The experience of economic development of new areas in Mexico, Venezuela and Brazil. Some regularities and differences] // Latinskaya Amerika: khozyaystvennoe osvoenie novykh territoriy [Latin America: economic development of new territories] / K.S. Tarasov, ed. Moscow: ILA AN SSSR. 189 p.

Ravuri E.D. (2001). Migration in Venezuela, 1950-1990: A Reassessment of the Guayana Project. University of Cincinnati. 471 p.

Regional'naya politika: zarubezhnyy opyt i rossiyskie realii [Regional Policy: Foreign Experience and Russian Realities] (2015) / A.V. Kuznetsov, O.V. Kuznetsova, eds. Moscow: IMEMO RAN. 137 p.

Sakevich V.I. (2018). Politika v oblasti reproduktivnogo zdorov'ya v regionakh i stranakh mira [Reproductive health policy in regions and countries of the world] // Demoscope Weekly. 777-778. URL: http://Demoscope.ru/weekly/2018/0777/barom01.php (accessed: 12.09.2018)

Scherbakova E.M. (2014). Mezhdunarodnaya migratsiya i migratsionnaya politika [International migration and migration policy] // Demoscope Weekly, 597-598. URL: http://Demoscope.ru/weekly/2014/0597/barometer597.pdf (accessed: 12.09.2018)

Shcherbakova E.M. (2016). Starenie naseleniya i ustoychivoe razvitie [Population aging and sustainable development] // Demoscope Weekly, 709-710. URL: http://www.Demoscope.ru/weekly/2016/0709/barometer709.pdf (accessed: 12.09.2018)

Soroko E.L. (2012). Kriterii kachestva demograficheskikh baz dannykh [Quality criteria for demographic databases] // Demograficheskoe razvitie: vyzovy globalizatsii. Sed'mye Valenteevskie chteniya. Materialy mezhdunarodnoy konferentsii. Moskva, 15-17 noyabria [Demographic development: challenges of globalization. The Seventh "Valenteevskiye Chteniya": International Conference. Moscow, November 2012: Proceedings] / V. Iontsev, N. Zvereva, G. Ananeva, V. Tyshkevitch, eds. Moscow: MAKS Press: 130-131.

Trends in International Migrant Stock: The 2015 Revision (2015). New York: United Nations Department of Economic and Social Affairs, Population Division. 
United Nations, Department of Economic and Social Affairs, Population Division (2016). Policies on spatial distribution and urbanization: Data Booklet (ST/ESA/ SER.A/394) URL: http://www.un.org/en/development/desa/population/publications/pdf/policy/Data\%20Booklet \%20Urbanization\%20Policies.pdf (accessed: 12.09.2018).

Vinnik M.V. (2012). Kakoy dolzhna byt' ideal'naya demograficheskaya baza dannykh? [What should be the ideal demographic database?] // Demoscope Weekly, 533-534. URL: http://www.Demoscope.ru/weekly/2012/0533/analit06.php (accessed: 12.09.2018).

World Population Policies Database: The 2015 Revision (2018). URL: https://esa.un.org/PopPolicy/about_database.aspx (accessed: 12.09.2018).

Zaydfudim P.Kh. (1993). Reabilitatsiya zhiznennoy sredy rossiyskogo Severa [Rehabilitation of the living environment of the Russian North]. Moscow: Goskomsever Rossii. 67 p.

Zayonchkovskaya Zh.A. (1991). Demograficheskaya situatsiya i rasselenie [Demographic situation and resettlement]. Moscow: Nauka. 135 p. 